\title{
Sectioned images and surface models of a cadaver for understanding the free vascularised anterior rib flap
}

\author{
D.S. Shin ${ }^{1}$, H.J. Kim² ${ }^{2}$ B.C. Kim ${ }^{3}$ \\ ${ }^{1}$ Department of Orthopaedic Biomaterial Science, Osaka University, Graduate School of Medicine, Osaka, Japan \\ 2Department of Oral and Maxillofacial Surgery, Yonsei University College of Dentistry, Seoul, Republic of Korea \\ ${ }^{3}$ Department of Oral and Maxillofacial Surgery, Daejeon Dental Hospital, Wonkwang University College of Dentistry, \\ Daejeon, Republic of Korea
}

[Received: 3 March 2016; Accepted: 6 June 2016]

Background: The purpose of this study is to describe the vascularised anterior rib flap on sectioned images and surface models using Visible Korean for medical education and clinical training in the field of mandibular reconstructive surgery. Materials and methods: Serially sectioned images of the thorax were obtained from a cadaver. Significant structures in the sectioned images were outlined and stacked to create a surface model.

Results: The PDF file (8.45 MB) of the assembled models can be downloaded for free from our website (http://vkh.ajou.ac.kr/Products/PDF/Vascularized_anterior_rib_flap.zip). In this file, important anatomical structures related to the vascularised anterior rib flap can be examined in the sectioned images. All surface models and stereoscopic structures of the vascularised anterior rib flap are expressed in real time.

Conclusions: We hope that these state-of-the-art sectioned images, outlined images, and surface models will help students and trainees gain a better understanding of the anatomy of the vascularised anterior rib flap (Folia Morphol, 2017; 76, 1: 117-122).

Key words: cross-sectional anatomy, 3-dimensional imaging, mammary arteries, free tissue flaps, mandibular reconstruction

\section{INTRODUCTION}

Mandibular reconstruction should aim at replacing both function and form [8]. Speech, appearance, and mastication should be considered during surgical planning. The position of the mandible is highly perceptible. Therefore, during reconstruction and tissue coverage, reproduction of the resected native tissue is critical to acquire better functional and aesthetic results [8]. However, these aims are difficult to accomplish when it comes to defects of the mandibular condyle.
The vascularised anterior rib flap, which is based on the anterior intercostal artery, has been well established by several authors $[4,9,18,19]$. Their studies have proven that the anterior rib graft can survive with the periosteal supply alone providing nutrient blood supply to the rib $[4,9,18,19]$. The vascularised anterior rib flap is an attractive option for condylar reconstruction because it successfully recreates the appropriate condylar contour. Moreover, it includes a vascular pedicle, which is long and of an appropriate

Address for correspondence: B.C. Kim, DDS, PhD, Department of Oral and Maxillofacial Surgery, Daejeon Dental Hospital, Wonkwang University College of Dentistry, 77 Dunsan-ro, Daejeon, Republic of Korea, 35233, e-mail: bck@wku.ac.kr 


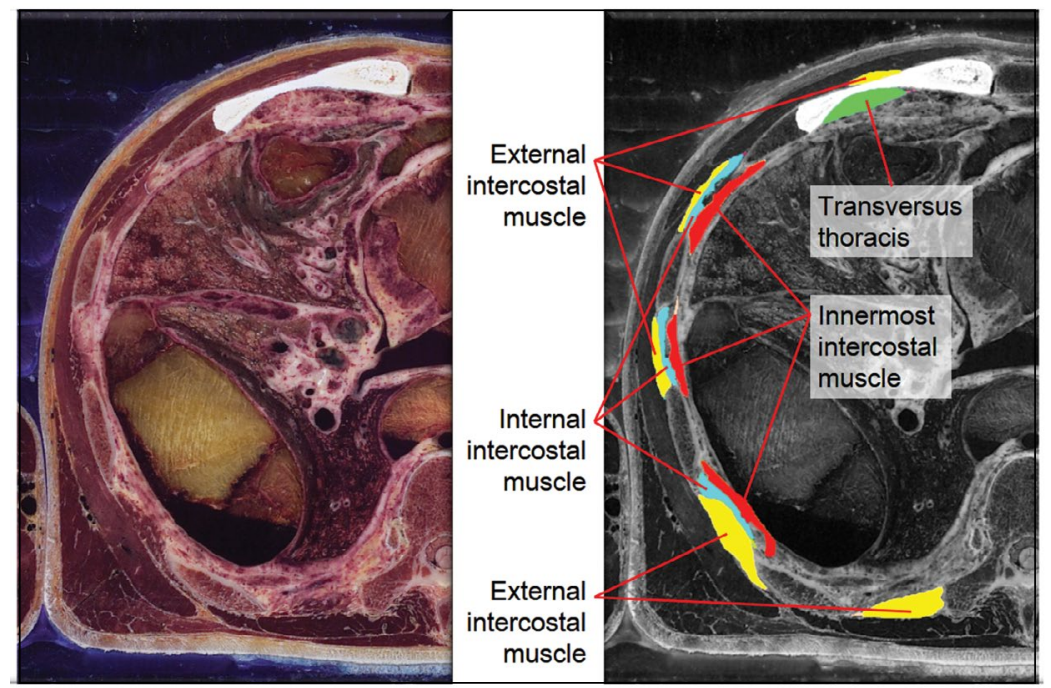

Figure 1. Sectioned and colour-coded images of the vascularised anterior rib flap.

diameter, of the anterior intercostal artery [20]. Moreover, the donor-site scars are positioned on the thorax and are more acceptable for patients who do not want a visible scar [19]. Therefore, the vascularised anterior rib flap is suitable for condylar reconstruction [19].

Despite these advantages, the vascularised anterior rib flap is seldom used for condylar reconstruction. Donor site morbidity, such as flail chest and pneumothorax, is the primary concern [19]. In addition, risky and tedious dissection limits the widespread acceptance of this flap [19]. As a result, medical students and trainees in mandibular reconstructive surgery have limited practical knowledge and experience. Therefore, a better understanding of the vascularised anterior rib flap anatomy may increase the use of this flap for mandibular reconstruction.

Meanwhile, coloured cross-sectional images at a resolution higher than that provided by computed tomography (CT) or magnetic resonance imaging (MRI) are helpful to create stereoscopic images that are useful for surgery. In a previous study, we produced Visible Korean images from thin-slice $0.2-\mathrm{mm}$ intervals) cross-sectional human datasets that were coloured similar to the in vivo structures $[6,7,16]$. Moreover, we created sectioned images and surface models of a cadaver thorax [13], and in another study, we reported software accessible by an untrained individual for searching sectional images by anatomic name [11]. These surface models were constructed as a portable document format (PDF) file using the software package Adobe Acrobat Pro Extended Version 9 (Adobe Systems, Inc., San Jose, CA, USA) [11].
Data obtained to date have not been able to effectively represent the vascularised anterior rib flap. Therefore, in this study, we developed sectioned images and stereoscopic surface models of the vascularised anterior rib flap for use in medical education and clinical training in the field of mandibular reconstructive surgery. Finally, the data will be accessible to maxillofacial surgeons and provide a better understanding of the vascularised anterior rib flap anatomy, ultimately upgrading surgical outcomes. Thorough anatomical knowledge maximises surgical predictability and allows surgeons to understand vascular reliability. In addition, the vascularised anterior rib flap can be virtually harvested using the PDF file described in this study.

\section{MATERIALS AND METHODS}

\section{Outlining of the images}

A progressive and advanced outlining technique was previously described $[6,7,16]$. In those studies, sectioned and outlined images of a male cadaver (0.2-mm intervals; 0.2 -mm pixels; 24-bit colour depth; resolution, 3,040 $\times 2,008$; tagged image file format [TIFF]) were created [17]. Only images of the thorax associated with the vascularised anterior rib flap were chosen for the present study.

Moreover, we manually produced outlined images of the vascularised anterior rib flap structures such as the anterior intercostal artery using Mimics software (Materialise, Inc., Leuven, Belgium) at 1-mm intervals with a 0.2 -mm pixel size (Fig. 1) $[6,7,16]$. The outlines of each structure were depicted by a specific colour, either semi-automatically or manually (Fig. 1) [12, 14, 15]. 
Table 1. Sixty-six surface models, categorised according to the systems and subsequent groups

\begin{tabular}{|c|c|c|}
\hline Systems & Groups & Structures \\
\hline Integumentary (2) & & Skin of trunk* ${ }^{*}$ Nipple $^{*}$ \\
\hline Muscular (8) & $\begin{array}{l}\text { Muscles of thorax } \\
\text { and abdomen (8) }\end{array}$ & $\begin{array}{l}\text { Pectoralis major*, Pectoralis minor*, Serratus anterior }{ }^{*} \text {, External intercostal muscle*, } \\
\text { Internal intercostal muscle*, Innermost intercostal muscle* }{ }^{*} \text {, Transversus thoracis*, } \\
\text { Diaphragm }\end{array}$ \\
\hline \multirow[t]{2}{*}{ Skeletal (25) } & Thoracic skeleton (24) & $\begin{array}{l}\text { Costal cartilage of first rib, First rib, Costal cartilage of second rib, Second rib, Costal carti- } \\
\text { lage of third rib, Third rib, Costal cartilage of fourth rib, Fourth rib, Costal cartilage of fifth rib, } \\
\text { Fifth rib, Costal cartilage of sixth rib, Sixth rib, Costal cartilage of seventh rib, Seventh rib, } \\
\text { Costal cartilage of eighth rib, Eighth rib, Costal cartilage of ninth rib, Ninth rib, Costal carti- } \\
\text { lage of tenth rib, Tenth rib, Costal cartilage of eleventh rib, Eleventh rib, Twelfth rib, Sternum }\end{array}$ \\
\hline & Bones of upper limb (1) & Clavicle \\
\hline Respiratory (1) & Lung and bronchi (1) & Right lung \\
\hline \multirow[t]{2}{*}{ Cardiovascular (20) } & Artery (10) & $\begin{array}{l}\text { Internal thoracic artery, First anterior intercostal artery, Second anterior intercostal artery, } \\
\text { Third anterior intercostal artery, Fourth anterior intercostal artery, Fifth anterior intercostal } \\
\text { artery, Sixth anterior intercostal artery, Seventh anterior intercostal artery, Eighth anterior } \\
\text { intercostal artery, Ninth anterior intercostal artery }\end{array}$ \\
\hline & Vein (10) & $\begin{array}{l}\text { Internal thoracic vein, First anterior intercostal vein, Second anterior intercostal vein, } \\
\text { Third anterior intercostal vein, Fourth anterior intercostal vein, Fifth anterior intercostal } \\
\text { vein, Sixth anterior intercostal vein, Seventh anterior intercostal vein, Eighth anterior } \\
\text { intercostal vein, Ninth anterior intercostal vein }\end{array}$ \\
\hline Nervous (10) & Peripheral nerves (10) & $\begin{array}{l}\text { Second intercostal nerve, Third intercostal nerve, Fourth intercostal nerve, Fifth inter- } \\
\text { costal nerve, Sixth intercostal nerve, Seventh intercostal nerve, Eighth intercostal nerve, } \\
\text { Ninth intercostal nerve, Tenth intercostal nerve, Eleventh intercostal nerve }\end{array}$ \\
\hline
\end{tabular}

In bracket — number of structures; ${ }^{*}$ Surface is made semi-transparent

\section{Reconstruction of surface models}

As previously reported, surface models of the thorax were created $[13,17]$. Additional surface models specific to the vascularised anterior rib flap were constructed in this study. Outlined images were also surface-reconstructed to enable their application in mandibular reconstructive surgery.

In total, 66 structures were subjected to surface reconstruction (Table 1) using Mimics software as described previously $[14,17]$. Then, the models were categorised and saved as stereolithography (STL) files and subsequently accessed using Maya software.

\section{Virtual harvesting of the anterior rib flap}

The reconstructed surface models were systematically painted to distinguish the combined structures on Maya (Table 1). The colours of muscles were kept semi-transparent to maintain the visibility of the inner structures (Fig. 2). The surface models were revised as required by an anatomist and a maxillofacial surgeon $[6,7,16]$. After painting, virtual harvesting of the vascularised anterior rib flap was performed (Fig. 3). The detailed procedure is described in the Results section.

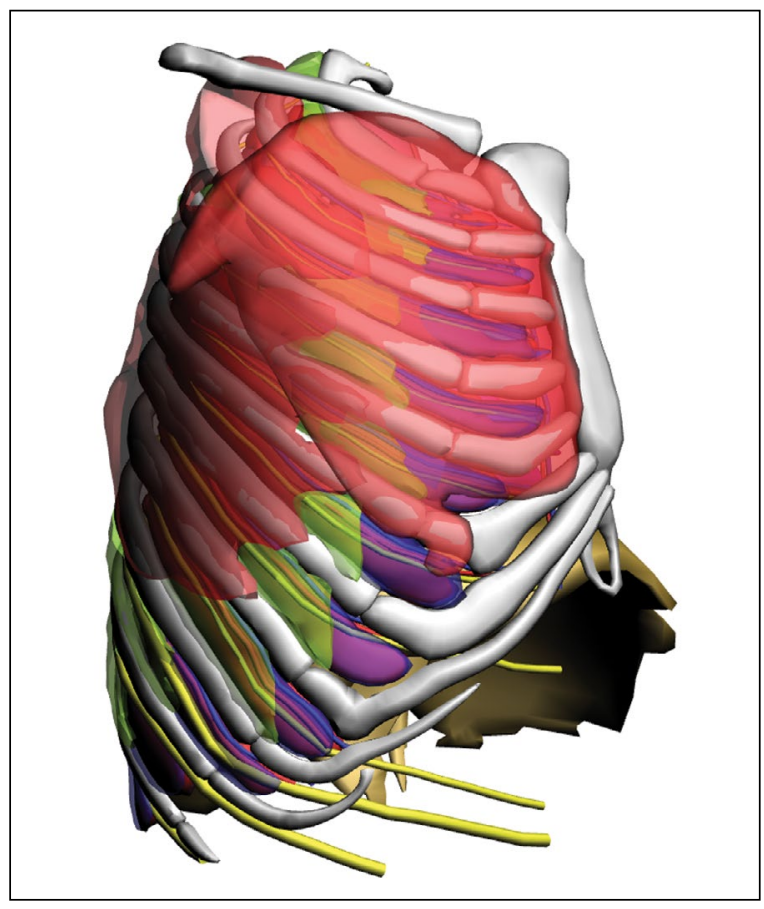

Figure 2. Surface models of the muscles are coloured semitransparent to reveal the inner anatomical structures. Pectoralis major, pectoralis minor, serratus anterior, and innermost intercostal muscle (red), external intercostal muscle (green), and internal intercostal muscle (magenta) are coloured as semi-trasparent. Bones (white), nerves (yellow), arteries (red), veins (blue), transversus thoracis (magenta), diaphragm (brown) are coloured as opaque. 


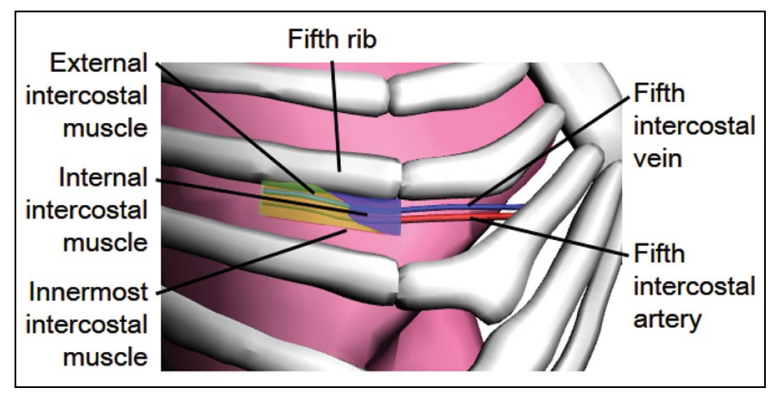

Figure 3. Stereolithography files for creating surface models depicting virtual harvesting of the vascularised anterior rib flap prepared using Maya software. A musculo-osseous free flap, including the fifth internal intercostal artery/vein, fifth rib, external intercostal muscle, internal intercostal muscle, and innermost intercostal muscle, are described.

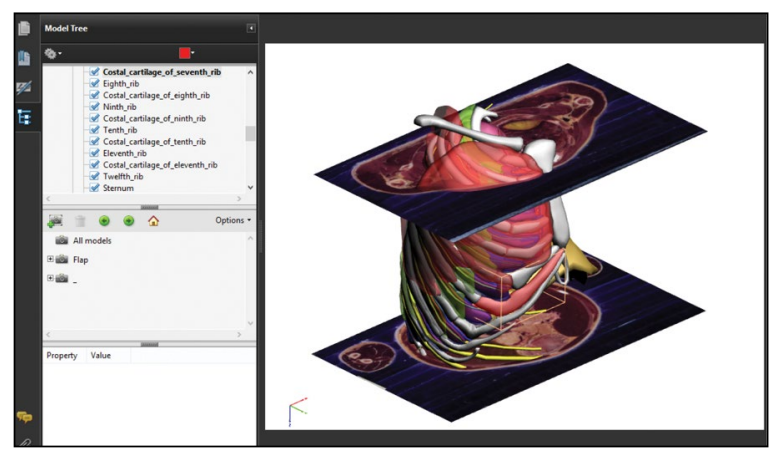

Figure 4. A PDF file for the vascularised anterior rib flap. Sectioned images and stereoscopic surface models of the vascularised anterior rib flap can be simultaneously or individually investigated.

\section{PDF file for the surface models}

Stereolithography files were classified by structure, and the surface models were anatomically arranged using Deep Exploration Standard (Right Hemisphere, San Ramon, CA, USA) [3]. The STL files were constructed and saved under the filename vascularized_anterior_rib_flap.pdf using 3D Reviewer, a software package accompanying Acrobat 9.0 Pro Extended (Adobe Systems, Inc., San Jose, CA, USA) $[12,14,15]$. Because the PDF file was accessed using Adobe Reader, the individual anatomical names and virtual harvesting of the vascularised anterior rib flap were described in the model tree window. In Acrobat, we constructed bookmarks for the flap and the name of associated structures (Fig. 4).

\section{RESULTS}

The PDF file (8.45 MB) is freely accessible from our website (http://vkh.ajou.ac.kr/Products/PDF/Vascularized_anterior_rib_flap.zip). In the sectioned images, structures associated with flap harvesting can be examined and are assessed as anatomically appropriate.

Moreover, the surface models and stereoscopic structures related to the vascularised anterior rib flap were described in real time. Significant anatomic structures can be easily inspected in the sectional images and stereoscopic aspects of the PDF file, as shown in the following examples.

In the sectioned images, users can measure the diameters of the anterior intercostal artery and vein, and investigate the vertical relationship between the vessels (Fig. 1). Furthermore, the users can estimate whether these vessels course between the innermost and internal intercostal muscles. With this knowledge, they can perceive that the diameters of the artery and vein are suitable for microanastomosis with the neck vessels, such as the facial artery and vein. In addition, their positional depth can be well understood.

On the stereoscopic surface models, the user can detect the course of the anterior intercostal artery, which branches from the internal thoracic artery as it exits from beneath the distal extensor retinaculum. The length of this artery was measured and considered appropriate for reconstruction of the condylar defect (Fig. 4). Moreover, it is located over the transversus thoracis muscle. Therefore, the user should take precautions while dissecting at this location to avoid complications such as pneumothorax. These images will help the user become accustomed to the vascularised anterior rib flap.

With this knowledge, users of the PDF file can understand the procedure for harvesting the vascularised anterior rib flap (Figs. 4, 5). A hockeystick-shaped incision is made over the chest wall, with the vertical limb directed over the root of the anterior intercostal artery. The fifth rib and two interspaces above and below it are revealed after dividing the pectoralis major and detaching the origin of the pectoralis minor. A segment of the costal cartilage is separated and subperichondrially eliminated. As dissection progresses, the underlying anterior intercostal artery should be identified and separated. Once the vascular pedicle is safely dissected, the intercostal muscles at the fourth and fifth intercostal spaces are incised below the fourth and above the sixth ribs, leaving as wide a cuff as possible for the fifth rib, both superiorly and inferiorly. The fifth rib is laterally cut as far as needed, and the vascularised rib is harvested from the pleura. The anterior intercostal artery is 


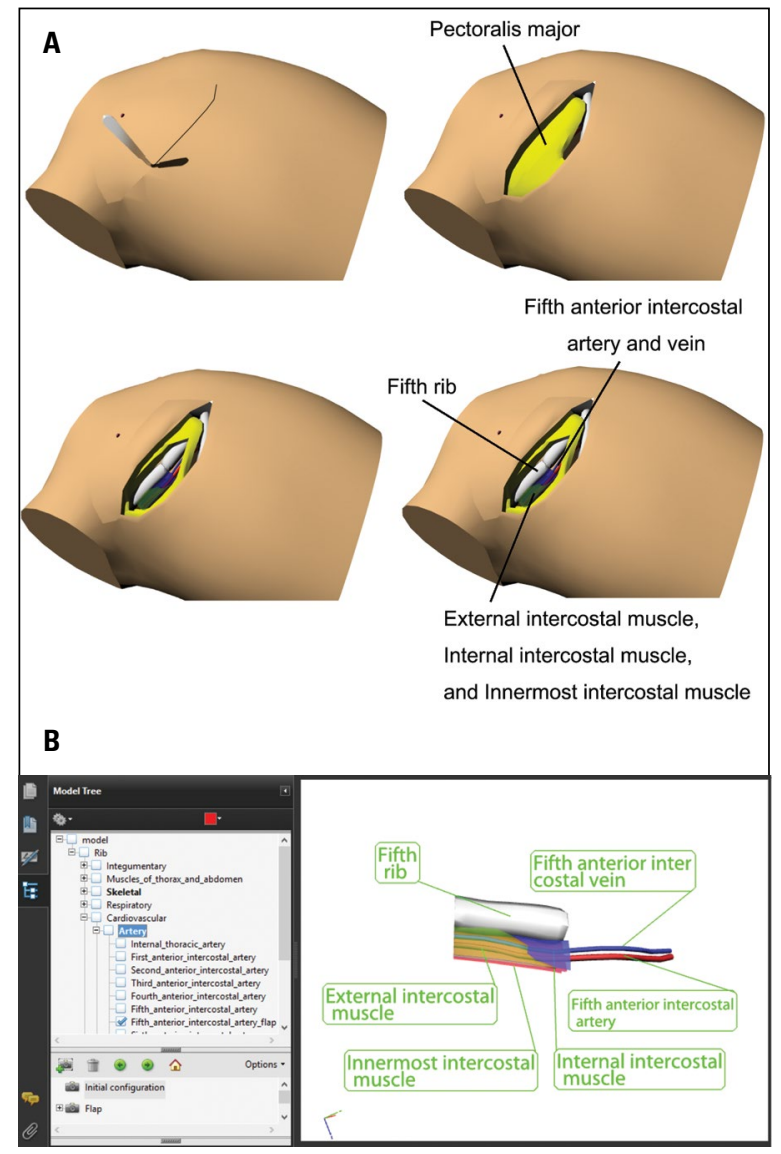

Figure 5. Animation and bookmark in the PDF file showing virtual harvesting of the vascularised anterior rib flap; $\mathbf{A}$. The thorax during flap harvesting; B. The vascularised anterior rib flap.

ligated at the junction with the internal thoracic artery. Finally, a musculo-osseous flap including the anterior intercostal artery, intercostal muscles, and rib is raised (Fig. 5).

\section{DISCUSSION}

The vascularised anterior rib flap is a useful option for microsurgical condylar reconstruction $[5,10,18$, 19]. Unfortunately, it remains an unpopular option for condylar reconstruction. As a result, medical students and trainees in oromandibular reconstructive surgery have limited knowledge and experience with this flap. Therefore, establishing a good foundation for anatomical knowledge on the vascularised anterior rib flap will prove beneficial, particularly for students and trainees.

The PDF file described in this study provides scientific data that can be manipulated offline, unlike other surface models such as Visiblebody or Zygotebody [1, 2]. Importantly, the surface models were assembled on the basis of scientific data. The models were created by outlining structures in serially sectioned images, stacking these outlines, and connecting the outlines using a polygon-based surface reconstruction method $[14,17]$. The resultant models are thorough and differ from currently accessible surface models, which are manually created by artists with anatomical knowledge. The surface models created by us also provide equivalent sectional images (Fig. 4).

Several complications may arise during vascularised anterior rib flap harvesting, such as flail chest or pneumothorax [19]. The internal intercostal artery is located over the transversus thoracis and innermost intercostal muscles. Furthermore, the sectioned images and surface models described in this study are appropriate for understanding the stereoscopic position of the internal intercostal artery. Therefore, complications can be decreased by a good understanding of this anatomy.

Clinically, there are little variations or individual differences in the anatomy of the anterior intercostal artery. However, especially in the female or obese, a lot of fat and/or glandular tissue were located under the skin of thorax. In these cases, skin incision should be performed more deeply than in the male or slim.

\section{CONCLUSIONS}

In conclusion, we anticipate that the surface models and sectioned images described in this study will enable a thorough understanding of the anatomy related to the vascularised anterior rib flap, ensuring better outcomes of mandibular reconstruction procedures using this flap. In particular, the results of this study will benefit students and trainees in mandibular reconstructive surgery and help them in thoroughly comprehending the principles underlying the use of the vascularised anterior rib flap.

\section{Acknowledgements}

This study was supported by Wonkwang University in 2016.

\section{REFERENCES}

1. http://www.visiblebody.com.

2. http://www.zygotebody.com.

3. FCAT (Federative Committee on Anatomical Terminology): Terminologia Anatomica: International Anatomical Terminology. Thieme, Stuttgart, New York, 1998. 
4. Ariyan S. The viability of rib grafts transplanted with the periosteal blood supply. Plast. Reconstr. Surg. 1980; 65(2): 140-151, doi: 10.1097/00006534-198002000-00004, indexed in Pubmed: 7352154.

5. Ariyan S, Finseth FJ. The anterior chest approach for obtaining free osteocutaneous rib grafts. Plast Reconstr Surg. 1978; 62(5): 676-685, doi:10.1097/00006534197811000-00002, indexed in Pubmed: 715018.

6. Kim BC, Chung MS, Kim HJ, et al. Sectioned images and surface models of a cadaver for understanding the deep circumflex iliac artery flap. J Craniofac Surg. 2014; 25(2): 626-629, doi: 10.1097/SCS.0000000000000645, indexed in Pubmed: 24621709.

7. Kim BC, Chung MS, Park HS, et al. Accessible and informative sectioned images and surface models of the maxillofacial area for orthognathic surgery. Folia Morphol. 2015; 74(3): 346-351, doi: 10.5603/FM.2015.0052, indexed in Pubmed: 26339816.

8. Kim BC, Kim S, Nam W, et al. Mandibular reconstruction with vascularized osseous free flaps: a review of the literature. Asian Pac J Cancer Prev. 2012; 13(2): 553-538, doi: 10.7314/ apjcp.2012.13.2.553, indexed in Pubmed: 22524823.

9. McKee DM. Microvascular bone transplatation. Clin Plast Surg. 1978; 5(2): 283-292, indexed in Pubmed: 354844.

10. Serafin D, Riefkohl R. Mandible reconstruction: vascularized rib-periosteal transplantation. In: Serafin D, Bunke HJ eds. Microsurgical composite tissue transplantation. C.V. Mosby, St. Louis, 1979; pp. 439-445.

11. Shin DS, Chung MS, Park HS, et al. Browsing software of the Visible Korean data used for teaching sectional anatomy. Anat Sci Educ. 2011; 4(6): 327-332, doi: 10.1002/ ase.249, indexed in Pubmed: 22065474.

12. Shin DS, Chung MS, Park JS. Systematized methods of surface reconstruction from the serial sectioned images of a cadaver head. J Craniofac Surg. 2012; 23(1): 190-194, doi: 10.1097/SCS.0b013e3182418e87, indexed in Pubmed: 22337405.
13. Shin DS, Chung MS, Park JS, et al. Portable document format file showing the surface models of cadaver whole body. J Korean Med Sci. 2012; 27(8): 849-856, doi: 10.3346/jkms.2012.27.8.849, indexed in Pubmed: 22876049.

14. Shin DS, Jang HG, Hwang SB, et al. Two-dimensional sectioned images and three-dimensional surface models for learning the anatomy of the female pelvis. Anat Sci Educ. 2013; 6(5): 316-323, doi: 10.1002/ase.1342, indexed in Pubmed: 23463707.

15. Shin DS, Jang HG, Park JS, et al. Accessible and informative sectioned images and surface models of a cadaver head. J Craniofac Surg. 2012; 23(4): 1176-1180, doi: $10.1097 /$ SCS.0b013e31825657d8, indexed in Pubmed: 22801119.

16. Shin DS, Kim HJ, Kim BC. Sectioned Images and Surface Models of a Cadaver for Understanding the Dorsalis Pedis Flap. J Craniofac Surg. 2015; 26(5): 1656-1659, doi: $10.1097 / \mathrm{SCS} .0000000000001618$, indexed in Pubmed: 26079120.

17. Shin DS, Park JS, Park HS, et al. Outlining of the detailed structures in sectioned images from Visible Korean. Surg Radiol Anat. 2012; 34(3): 235-247, doi: 10.1007/s00276011-0870-2, indexed in Pubmed: 21947014.

18. Song $R$, Lu C, Song $Y$, et al. Repair of large mandibular defects with vascularized rib grafts. Clin Plast Surg. 1982; 9(1): 73-78, indexed in Pubmed:7094529.

19. Thoma A, Heddle S, Archibald S, et al. The free vascularized anterior rib graft. Plast Reconstr Surg. 1988; 82(2): 291-298, doi: 10.1097/00006534-198808000-00014, indexed in Pubmed: 3399558.

20. Weiland AJ, Berggren A, Jones L. The acute effects of blocking medullary blood supply on regional cortical blood flow in canine ribs as measured by the hydrogen washout technique. Clin Orthop Relat Res. 1982(165): 265-272, doi: 10.1097/00003086-198205000-00041, indexed in Pubmed:7075070. 